\title{
Simulating Three-Dimensional Plume Migration of a Radionuclide Decay Chain through Groundwater
}

\author{
Jui-Sheng Chen ${ }^{1, *}$, Ching-Ping Liang ${ }^{2, *}$, Cheng-Hung Chang ${ }^{1}$ and Ming-Hsien Wan ${ }^{3}$ \\ 1 Graduate Institute of Applied Geology, National Central University, Jhongli District, Taoyuan 32001, Taiwan; \\ sosohung20@gmail.com \\ 2 Department of Nursing, Fooyin University, Kaohsiung 83101, Taiwan \\ 3 Fuel Cycle and Materials Administration, Atomic Energy Council, Taipei 23452, Taiwan; \\ wmshan@aec.gov.tw \\ * Correspondence: jschen@geo.ncu.edu.tw (J.-S.C.); sc048@fy.edu.tw (C.-P.L.); Tel.: +886-3-2807427 (J.-S.C.); \\ +886-7-7811151-7026(C.-P.L.)
}

Received: 24 August 2019; Accepted: 27 September 2019; Published: 30 September 2019

\begin{abstract}
In this study, we present a semi-analytical model for simulating three-dimensional radioactivity transport of a radionuclide decay chain and assessing the radiological dose impact on the general public. The mechanisms and processes considered in the model include the one-dimensional advection, hydrodynamic dispersion in longitudinal and two lateral directions, linear equilibrium sorption, and first-order radioactive decay reactions. The semi-analytical model is derived for a semi-infinite domain, and the solutions in the Laplace domain for members of the decay chain are first generalized in a compact format. The concentrations in the original domain of each nuclide are independently evaluated with the help of the efficient and robust Laplace numerical inverse algorithms. The accuracy of the derived semi-analytical model is demonstrated by comparison of our developed model with an existing analytical model described in the literature. The results of the verification exercise indicate that the derived semi-analytical model is accurate and robust. The developed semi-analytical model is applied to an illustrative example that simulates the three-dimensional plume migration of a radionuclide decay chain on both the temporal and spatial scales. Moreover, the time histories of the radiological doses at different distances from the inflow source boundary are presented to understand the potential radiological impact on the general public. The developed model facilitates rapid assessment of the radiological impact posed by the presence of radionuclides in the environment because of leakage from a nuclear waste repository or accidental discharges from nuclear facilities.
\end{abstract}

Keywords: analytical model; radionuclide decay chain; advection-dispersion equation; first-order decay reaction; radiological dose

\section{Introduction}

Nuclear technology has been extensively employed for the development of nuclear weapons, production of electricity, medical and industrial applications, as well as a variety of other civilian uses for approximately seventy years. Although society has greatly benefited from the use of nuclear technology, there exist potential risks posed by the presence of radionuclides in the environment, whether released from nuclear waste repositories or through accidental discharges from various nuclear facilities including nuclear power plants, fuel reprocessing plants, and uranium mining and milling operations. It is important to build a reliable emergency and long-term risk management system for assessing the radiation dose received by the people. Groundwater is one of the most important environmental media for the transport of radionuclides after their release from waste disposal areas 
or from certain classes of accidental releases from nuclear facilities. Actual observation of long-term transport behavior of radionuclides released from the waste disposal areas cannot be performed however. Groundwater transport models along with experiments, measurements, and observations performed in the field provide efficient means to calculate the expected radioactivity concentration of radionuclides following their release into the groundwater. The groundwater transport model for simulating the long-term radioactivity transport can be developed by solving the transport governing equations using analytical solutions or numerical approaches. Despite their inherent limitation to homogeneous media with relatively simple and regular geometries, analytical models are more rapid and efficient tools for predicting the long-term concentration of radioactivity at specific points as compared with time-marching numerical models which generally require an extremely large number of time steps and place severe demands on computational time. The analytical groundwater transport model can be used for certain types of analyses where the currently available data do not warrant a more complicated study. Such models may frequently be adequate for regulatory needs provided the model parameters are chosen conservatively.

Numerous analytical groundwater transport models have been reported in the literature for the simplified case of unidirectional groundwater flow with one-, two-, and three-dimensional hydrodynamic dispersion in saturated and homogeneous geological media [1-23]. However, such analytical groundwater transport models have mostly been derived for a single dissolved substance. Radionuclides decay into other radioactive products or stable species, called daughter species or progeny. The chain decay processes of radionuclides are particularly important for modeling the transport of actinides and transuranics. The parent-daughter interactions are neglected in the analytical groundwater transport models that account for the transport of only a single dissolved substance, thus leading to significant error in the predicted transport behaviors of all members of a radionuclide decay chain. Nair et al. [24] developed a numerical model for simulating three-dimensional radioactivity transport of a long radionuclide decay chain with consideration of distinct retardation factors for each individual nuclide and showed that the model with decay chain transport gives total effective doses about 1000 times higher than those calculated using a model without decay chain transport. This showed the importance of the inclusion of decay chain transport in modeling the radionuclide in the subsurface system.

In order to incorporate the chain decay processes of radionuclides, the advection-dispersion transport equation for each progeny must include the term for ingrowth from the preceding parent radionuclides. Analytical groundwater transport models that use a set of advection-dispersion equations sequentially coupled with radioactive decay reactions can serve as rapid tools for simultaneously simulating the long-term transport behaviors of the original species and its progeny of a radionuclide decay chain. However, only a few analytical solutions solved for coupled multiple radionuclide transport equations are currently available in the literature for evaluating the radionuclide decay chain migration. Developing analytical models for predicting the radionuclide decay chain transport generally involves cumbersome and complicated mathematical manipulations because of the need to solve a system of coupled advection-dispersion equations simultaneously.

Most of the analytical models for the decay chain transport currently reported in the literature are limited to one-dimensional advective-dispersive transport [17,25-35]. Multidimensional models for decay chain transport for radionuclide decay chains would be much more suited for real-world applications. Bauer et al. [36] presented a pioneering analytical model for one-, two-, and three-dimensional decay chain transport. Montas [37] presented an analytical model for three-dimensional advection-dispersion equations coupled with first-order decay reactions for a three-species decay chain. Quezada et al. [38] extended Clement's [31] solution technique to derive analytical solutions in the Laplace domain for a decay chain with an arbitrary number of members. Sudicky et al. [39] presented a semi-analytical model for investigating the three-dimensional plume migration of a decay chain subject to a first-type inflow boundary condition, but their model was limited to four-level decay chain and did not obtain generalized expressions for arbitrary target species. 
It should also be noted that the first-type inflow boundary condition generally causes mass conservation errors, especially for a subsurface system with a large longitudinal dispersion coefficient [40-43]. Chen et al. [44] developed an exact analytical model for the two-dimensional plume migration of a decay chain in a finite-length system subject to a third-type inflow source boundary condition. A concise mathematical expression for an arbitrary member of a decay chain was obtained, but the solution involves the summations of three infinite series expansions. Numerical evaluations of the analytical solutions derived for a finite-length domain with a summation of infinite series expansion are always time-consuming and computationally inefficient [45-47].

Based on the literature review, this study develops a semi-analytical model for rapidly simulating the three-dimensional radioactivity transport of a radionuclide decay chain. The derived semi-analytical model includes a general mathematical expression for an arbitrary member of a radionuclide decay chain, making it easy to write a computer program code for implementing the computation. The novelty of the developed semi-analytical model is three-fold. First, the solutions are computationally efficient. Second, the solution can evaluate concentration for larger Peclet values. Third, the solutions are derived for three-dimensional radionuclide transport, which has more practical applications. The derived analytical model should have more practical applications for a rapid evaluation of the concentration of radioactivity on a spatial and a temporal scale as well as the radiological dose for a real-world radionuclide decay chain.

\section{Mathematical Model}

This study considers the movements of the original radionuclide and its serial progeny, sequentially coupled by the first-order radioactive decay reactions, producing a radionuclide decay chain. Assuming a homogeneous aquifer with a steady and unidirectional flow field moving along the $x$ direction with three dispersion regions along the $x, y$, and $z$ directions, as schematically described in Figure 1, the governing equations for the ith member of a radionuclide decay chain can be expressed as

$$
\begin{gathered}
D_{x} \frac{\partial^{2} C_{1}(x, y, z, t)}{\partial x^{2}}+D_{y} \frac{\partial^{2} C_{1}(x, y, z, t)}{\partial y^{2}}+D_{z} \frac{\partial^{2} C_{1}(x, y, z, t)}{\partial z^{2}} \\
-v \frac{\partial C_{1}(x, y, z, t)}{\partial x}-\lambda_{1} R_{1} C_{1}(x, y, z, t)=R_{1} \frac{\partial C_{1}(x, y, z, t)}{\partial t} \\
D_{x} \frac{\partial^{2} C_{i}(x, y, z, t)}{\partial x^{2}}+D_{y} \frac{\partial^{2} C_{i}(x, y, z, t)}{\partial y^{2}}+D_{z} \frac{\partial^{2} C_{i}(x, y, z, t)}{\partial z^{2}} \\
-v \frac{\partial C_{i}(x, y, z, t)}{\partial x}-\lambda_{i} R_{i} C_{i}(x, y, z, t)+\lambda_{i-1} R_{i-1} C_{i-1}(x, y, z, t), \\
=R_{i} \frac{\partial C_{i}(x, y, z, t)}{\partial t} \\
i=2
\end{gathered}
$$

where $C_{i}(x, y, z, t)$ represents the radioactivity concentration of nuclide $i\left[\mathrm{~Bq} / \mathrm{m}^{3}\right] ; x, y, z$ denote the three spatial coordinates $[\mathrm{m}]$, respectively; $t$ is time $[y] ; D_{x}, D_{y}$, and $D_{z}$ are the hydrodynamic dispersion coefficient in the $x, y$ and $z$ directions; $v$ is the linear average seepage velocity; $\lambda_{i}$ is the radioactive decay constant of nuclide $i\left[\mathrm{y}^{-1}\right] ; R_{i}$ is the retardation factor of nuclide $i[-] ; N$ is the total number of the nuclides involved in the radionuclide decay chain. 


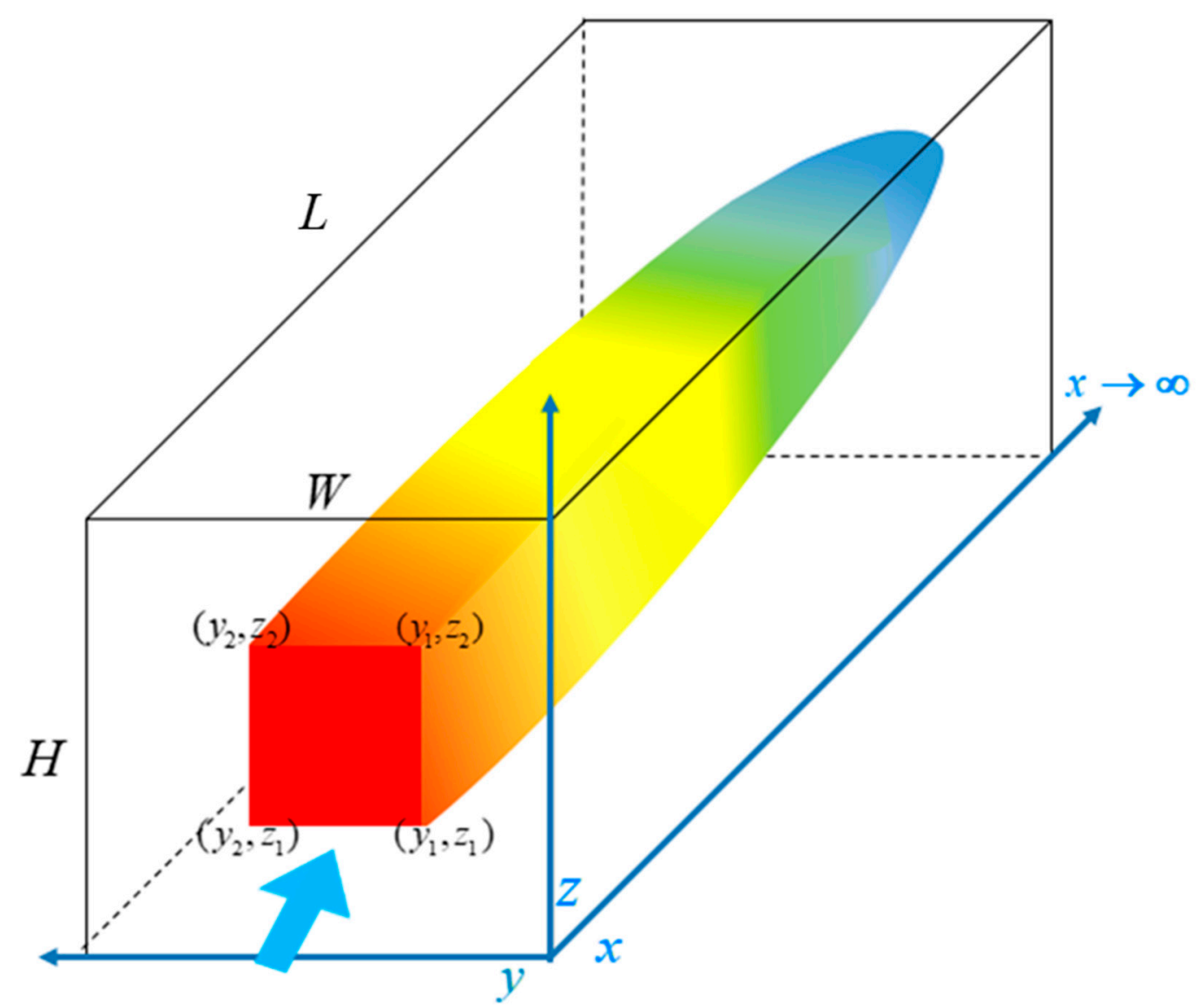

Figure 1. Schematic view of the three-dimensional plume migration of a radionuclide decay chain.

It is assumed that the aquifer is free of radionuclides before their release from the source area and can be stated as

$$
C_{i}(x, y, z, t=0)=0, \quad i=1, \ldots, N
$$

When simulating the transport of a radionuclide decay chain, the radionuclide sources are important because they govern the magnitude of the radioactivity concentrations and the shapes and sizes of the nuclide plumes. Herein, we consider a source region that contains specified amounts of the nuclide sources per cross-sectional area perpendicular to the groundwater flow direction and assume the release rate of each nuclide is proportional to the amounts of nuclides staying in the repository. A set of coupled equations is used to compute the total amount of each nuclide member as a function of time. The coupled equations and their required initial conditions can be mathematically expressed as follows [24,48]:

$$
\begin{gathered}
\frac{d M_{1}(t)}{d t}=-\lambda_{1} M_{1}(t)-\gamma_{1} M_{1}(t) \\
\frac{d M_{i}(t)}{d t}=\lambda_{i-1} M_{i-1}(t)-\lambda_{i} M_{i}(t)-\gamma_{i} M_{i}(t), \quad i=2, \ldots, N \\
M_{i}(t=0)=M_{i}^{0}, \quad i=1, \ldots, N
\end{gathered}
$$

where $M_{i}(t)$ is the amount of nuclide $i$ per unit cross-sectional area perpendicular to the groundwater flow direction at time $t\left[\mathrm{~Bq} / \mathrm{m}^{2}\right] ; \gamma_{i}$ is the proportionality constant for nuclide $i$ that quantifies the release rate from the repository, and $M_{i}^{0}$ is the amount of nuclide $i$ at the initial time. 
In this study, the release of the radionuclide is considered as an inflow source boundary condition. Based on the continuity of the radioactivity flux for each nuclide across the source boundary, a third-type inflow boundary condition can be specified as

$$
\varphi v C_{i}(x=0, y, z, t)-\varphi D_{x} \frac{\partial C_{i}(x=0, y, z, t)}{\partial x}= \begin{cases}\gamma_{i} M_{i}(t) & y_{1} \leq y \leq y_{2}, z_{1} \leq z \leq z_{2} \\ 0 & \text { elsewhere }\end{cases}
$$

where $\varphi$ is the effective porosity.

Boundary conditions for all species are set at infinity as follows:

$$
C_{i}(x \rightarrow \infty, y, z, t)=0
$$

The other boundary conditions required for obtaining unique solutions to Equations (1) and (2) are

$$
\begin{aligned}
& \frac{\partial C_{i}(x, y=0, z, t)}{\partial y}=\frac{\partial C_{i}(x, y=W, z, t)}{\partial y}=0 \\
& \frac{\partial C_{i}(x, y, z=0, t)}{\partial z}=\frac{\partial C_{i}(x, y, z=H, t)}{\partial z}=0
\end{aligned}
$$

Using $X=\frac{x}{L}, Y=\frac{y}{W}, Z=\frac{z}{H}, T=\frac{t}{\frac{L}{v}}=\frac{v t}{L}$, we can express Equations (1)-(10) in dimensionless form as

$$
\begin{aligned}
& \frac{1}{P e_{x}} \frac{\partial^{2} C_{1}(X, Y, Z, T)}{\partial X^{2}}+\frac{\eta_{y}{ }^{2}}{P e_{y}} \frac{\partial^{2} C_{1}(X, Y, Z, T)}{\partial Y^{2}}+\frac{\eta_{z}{ }^{2}}{P e_{z}} \frac{\partial^{2} C_{1}(X, Y, Z, T)}{\partial Z^{2}} \\
& -\frac{\partial C_{1}(X, Y, Z, T)}{\partial X}-\mu_{1} R_{1} C_{1}(X, Y, Z, T)=R_{1} \frac{\partial C_{1}(X, Y, Z, T)}{\partial T} \\
& \frac{1}{P e_{x}} \frac{\partial^{2} C_{i}(X, Y, Z, T)}{\partial X^{2}}+\frac{\eta_{y}^{2}}{P e_{y}} \frac{\partial^{2} C_{i}(X, Y, Z, T)}{\partial Y^{2}}+\frac{\eta_{z}^{2}}{P e_{z}} \frac{\partial^{2} C_{i}(X, Y, Z, T)}{\partial Z^{2}} \\
& -\frac{\partial C_{i}(X, Y, Z, T)}{\partial X}-\mu_{i} R_{i} C_{i}(X, Y, Z, T)+\mu_{i-1} R_{i-1} C_{i-1}(X, Y, Z, T) \\
& =R_{i} \frac{\partial C_{i}(X, Y, Z, T)}{\partial T} \\
& C_{i}(X, Y, Z, T=0)=0, \quad i=1, \ldots, N \\
& \frac{d M_{1}(T)}{d T}=-\mu_{1} M_{1}(T)-\delta_{1} M_{1}(T) \\
& \frac{d M_{i}(T)}{d T}=\mu_{i-1} M_{i-1}(T)-\mu_{i} M_{i}(T)-\delta_{i} M_{i}(T), i=2, \ldots, N \\
& M_{i}(T=0)=M_{i}^{0}, i=1, \ldots, N \\
& C_{i}(X=0, Y, Z, T)-\frac{1}{P e} \frac{\partial C_{i}(X=0, Y, Z, T)}{\partial X}= \begin{cases}\frac{\gamma_{i}}{v \phi} M_{i}(T) & Y_{1} \leq Y \leq Y_{2}, Z_{1} \leq Z \leq Z_{2} \\
0 & \text { elsewhere }\end{cases} \\
& C_{i}(X \rightarrow 0, Y, Z, T)=0 \\
& \frac{\partial C_{i}(X, Y=0, Z, T)}{\partial Y}=\frac{\partial C_{i}(X, Y=1, Z, T)}{\partial Y}=0 \\
& \frac{\partial C_{i}(X, Y, Z=0, T)}{\partial Z}=\frac{\partial C_{i}(X, Y, Z=1, T)}{\partial Z}=0
\end{aligned}
$$

where $P e_{x}=\frac{v L}{D_{x}}, P e_{y}=\frac{v L}{D_{y}}, P e_{y}=\frac{v L}{D_{y}}, \eta_{y}^{2}=\frac{L^{2}}{W^{2}}, \eta_{z}^{2}=\frac{L^{2}}{H^{2}}, \mu_{i}=\frac{\lambda_{i} L}{v}$ and $\delta_{i}=\frac{\gamma_{i} L}{v}$.

The solution strategy for solving Equations (11)-(20) involves conversion of the coupled partial differential equations (PDEs) into a set of simultaneous ordinary differential equations (ODEs) via a series of integral transform, after which the solutions can be easily obtained. The solution for radioactivity concentration of each individual nuclide in the transformed domain can then be sequentially obtained by applying the general approach for solving a set of second-order ODE with constant coefficients. 
Taking the Laplace transforms on Equations (11), (12), (14), and (15) with respect to $T$ and substituting the initial conditions as defined in Equations (13) and (16) for $\overline{C_{i}}(X, Y, Z, s)$ and $\overline{M_{i}}(T)$, respectively, yields

$$
\begin{gathered}
\frac{1}{P e_{x}} \frac{\partial^{2} \overline{C_{1}}(X, Y, Z, s)}{\partial X^{2}}+\frac{\eta y^{2}}{P e_{y}} \frac{\partial^{2} \overline{C_{1}}(X, Y, Z, s)}{\partial Y^{2}}+\frac{\eta_{z}{ }^{2}}{P e_{z}} \frac{\partial^{2} \overline{C_{1}}(X, Y, Z, s)}{\partial Z^{2}} \\
-\frac{\partial \overline{C_{1}}(X, Y, Z, s)}{\partial X}-\left(s R_{1}+\mu_{1} R_{1}\right) \overline{C_{1}}(X, Y, Z, s)=0 \\
\frac{1}{P e_{x}} \frac{\partial^{2} \overline{C_{i}}(X, Y, Z, s)}{\partial X^{2}}+\frac{\eta_{y}{ }^{2}}{P e_{y}} \frac{\partial^{2} \overline{C_{i}}(X, Y, Z, s)}{\partial Y^{2}}+\frac{\eta_{z}{ }^{2}}{P e_{z}} \frac{\partial^{2} \overline{C_{i}}(X, Y, Z, s)}{\partial Z^{2}} \\
-\frac{\partial \overline{C_{i}}(X, Y, Z, s)}{\partial X}-\left(s R_{i}+\mu_{i}\right) \overline{C_{i}}(X, Y, Z, s)=-\mu_{i-1} R_{i-1} \overline{C_{i-1}}(X, Y, Z, s) \\
i=2, \ldots, N \\
\overline{M_{1}}(s)=\frac{M_{1}^{0}}{s+\psi_{1}} \\
\overline{M_{i}}(s)=\frac{\mu_{i-1} \overline{M_{i-1}}(s)+M_{i}^{0}}{s+\psi_{i}}, i=2, \ldots, N
\end{gathered}
$$

where $\psi_{i}=\mu_{i}+\delta_{i}$.

The Laplace transform of $\overline{C_{i}}(X, Y, Z, s)$ and $\overline{M_{i}}(s)$ is defined as

$$
\begin{aligned}
\overline{C_{i}}(X, Y, Z, s) & =\int_{0}^{\infty} e^{-s T} C_{i}(X, Y, Z, T) d T \\
\overline{M_{i}}(s) & =\int_{0}^{\infty} e^{-s T} M_{i}(T) d T
\end{aligned}
$$

where $s$ represents the Laplace transform parameter.

The transformed boundary conditions from Equations (17)-(20) turn into

$$
\begin{gathered}
\overline{C_{i}}(X=0, Y, Z, s)-\frac{1}{P e_{x}} \frac{\partial \overline{C_{i}}(X=0, Y, Z, s)}{\partial X}= \begin{cases}\frac{\gamma_{i}}{v \phi} \overline{M_{i}}(s) & Y_{1} \leq Y \leq Y_{2}, Z_{1} \leq Z \leq Z_{2} \\
0 & \text { elsewhere }\end{cases} \\
\overline{C_{i}(X \rightarrow \infty, Y, Z, s)=0} \\
\frac{\partial \overline{C_{i}}(X, Y=0, Z, s)}{\partial Y}=\frac{\partial \overline{C_{i}}(X, Y=1, Z, s)}{\partial Y}=0 \\
\frac{\partial \overline{C_{i}}(X, Y, Z=0, s)}{\partial Z}=\frac{\partial \overline{C_{i}}(X, Y, Z=1, s)}{\partial Z}=0
\end{gathered}
$$

Solving for $\overline{M_{i}}(s)$ in sequence using Equations (23) and (24), one has

$$
\overline{M_{i}}(s)=\frac{M_{i}^{0}}{s+\lambda_{i}}+\sum_{k=1}^{k=i-1} \frac{M_{i-k_{j=1}^{0}}^{0} \prod_{j=k}^{j=k} \mu_{i-j}}{\prod_{j=0}^{j=k} s+\lambda_{i-j}}
$$

Considering the second-order derivatives of the second and third terms of Equations (21) and (22), we apply the finite Fourier cosine transform twice with respect to $Y$ and $Z$ on Equations (21) and (22) [48]. This leads to

$$
\frac{1}{P e_{x}} \frac{d^{2} \overline{\overline{C_{1}}}(X, m, n, s)}{d X^{2}}-\frac{d \overline{\overline{C_{1}}}(X, m, n, s)}{d X}-\Theta_{1}(m, n, s) \overline{\overline{C_{1}}}(X, m, n, s)=0
$$




$$
\frac{1}{P e_{x}} \frac{d^{2} \overline{\overline{C_{i}}}(X, m, n, s)}{d X^{2}}-\frac{d \overline{\overline{C_{i}}}(X, m, n, s)}{d X}-\Theta_{2}(m, n, s) \overline{\overline{C_{i}}}(X, m, n, s)=-\mu_{i-1} \overline{\overline{C_{i-1}}}(X, m, n, s)
$$

The double finite Fourier cosine transform of $\overline{C_{i}}(X, Y, Z, s)$ is mathematically represented as

$$
\overline{\overline{C_{i}}}(X, m, n, s)=F_{Y Z}\left[\overline{C_{i}}(X, Y, Z, s)\right]=\int_{0}^{1}\left[\int_{0}^{1} C_{i}(X, Y, Z, s) \cos (m \pi Y) d Y\right] \cos (n \pi Z) d Z
$$

where $m$ and $n$ are two finite Fourier cosine transform parameters for $Y$ and $Z$, respectively, and $\Theta_{i}(m, n, s)=s R_{i}+\mu_{i}+\frac{\eta_{y}{ }^{2} m^{2} \pi^{2}}{P e_{y}}+\frac{\eta_{z}{ }^{2} n^{2} \pi^{2}}{P e_{z}}$.

Equations (32) and (33) are solved subject to the following boundary conditions that are the double finite Fourier cosine transform of Equations (27) and (28)

$$
\begin{gathered}
\overline{\overline{C_{i}}}(X=0, m, n, s)-\frac{1}{P e_{x}} \frac{d \overline{\overline{C_{i}}}(X=0, m, n, s)}{d X}=\frac{\gamma_{i} \psi(m) \zeta(n) \overline{M_{i}}(s)}{v \phi} \\
\overline{\overline{C_{i}}}(X \rightarrow \infty, m, n, s)=0
\end{gathered}
$$

where $\psi(m)=\left\{\begin{array}{c}Y_{2}-Y_{1} m=0 \\ \frac{\sin \left(m \pi Y_{2}\right)}{m}-\frac{\sin \left(m \pi Y_{1}\right)}{m} m=1,2, \ldots\end{array}\right.$ and $\zeta(n)=\left\{\begin{array}{c}Z_{2}-Z_{1} n=0 \\ \frac{\sin \left(n \pi Y_{2}\right)}{n}-\frac{\sin \left(n \pi Z_{1}\right)}{n} n=1,2, \ldots\end{array}\right.$

The standard mathematical approach for solving a second-order ODE with constant coefficient is used to obtain the solution $\overline{\overline{C_{i}}}(X, m, n, s)$ to Equations (32) and (33). Details of the derivation are omitted herein. The analytical solutions for an arbitrary member of a radionuclide decay chain can be generalized in a concise format as follows:

$$
\overline{\overline{\overline{C_{i}}}}(X, m, n, s)=H_{i} e^{\alpha_{i} X}+\sum_{n=1}^{n=i-1} P_{i, i-n} e^{\alpha_{i-n} X}
$$

where

$$
\begin{gathered}
\alpha_{i}=\frac{P e_{x}-\sqrt{P e_{x}^{2}-4 P e_{x} \Theta_{i}(m, n, s)}}{2} \\
H_{i}=\frac{\frac{\gamma_{i}}{v \phi} \psi(m) \zeta(n) \overline{M_{i}}(s)-\sum_{n=1}^{n=i-1} P_{i, i-n}\left(1-\frac{\alpha_{i-n}}{P e_{x}}\right)}{1-\frac{\alpha_{i}}{P e_{x}}} \\
P_{i, i-j}= \begin{cases}-\frac{\mu_{i-1} H_{i-1}}{\frac{\alpha_{i-1}{ }^{2}}{P_{e_{x}}}-\alpha_{i-1}-\Theta_{i}(m, n, s)} & j=i-1 \\
-\frac{\alpha_{i-1} P_{i-1, j}}{\frac{\alpha_{j}^{2}}{P e_{x}}-\alpha_{j}-\Theta_{i}(m, n, s)} & j \neq i-1\end{cases}
\end{gathered}
$$

Concise expressions for the target radionuclide described in Equations (37)-(40) are helpful to develop a Fortran computer program code for implementing the numerical evaluation.

The solutions in the original domain are obtained by using the double finite Fourier cosine inverse transforms and the Laplace inverse transform. This results in

$$
\begin{gathered}
C_{i}(X, Y, Z, T)=L^{-1}\left[\overline{C_{i}}(X, Y, Z, s)\right]=L^{-1}\left[F_{Y Z}{ }^{-1}\left[\overline{\overline{C_{i}}}(X, m, n, s)\right]\right] \\
=\left[L^{-1}\left[\overline{\overline{C_{i}}}(X, m=0, n=0, s)\right]+2 \sum_{n=1}^{n=\infty} L^{-1}\left[\overline{\overline{C_{i}}}(X, m=0, n, s)\right] \cos (n \pi Z)\right] \\
+\sum_{m=1}^{m=\infty}\left[L^{-1}\left[\overline{\overline{C_{i}}}(X, m, n=0, s)\right]+2 \sum_{n=1}^{n=\infty} L^{-1}\left[\overline{\overline{C_{i}}}(X, m, n, s)\right] \cos (n \pi Z)\right] \cos (m \pi Y)
\end{gathered}
$$


The analytical solution in the original domain can be obtained by performing the Laplace inverse transform on Equation (41). Although it seems to be difficult to perform analytical Laplace inversion, it can be transformed into the time domain by use of a numerical Laplace inverse algorithm such as the one developed by de Hoog et al. [49]. Several studies have demonstrated that the de Hoog et al. [49] lgorithm can give an accurate and temporally continuous evaluation of the solution $[9,14,50]$.

\section{Results and Discussion}

\subsection{Verification of the Developed Analytical Solution}

A computer program code was written with FORTRAN programming language to evaluate Equation (41). Prior to applying the developed analytical model to simulate the three-dimensional radioactivity transport of a radionuclide decay chain, we test the correctness of the derived semi-analytical model and the robustness of its corresponding computer program code by comparing them with an existing analytical model developed by Chen et al. [14] for simulating two-dimensional multispecies reactive transport in a finite-length groundwater system. The test example was selected from an illustrative example of an important radionuclide decay chain first described by Higashi and Pigford [51], to demonstrate the applicability of their developed multispecies analytical transport models. The illustrative example used by Higashi and Pigford [51] considers the hydrogeological transport of a four-member radionuclide chain of ${ }^{238} \mathrm{Pu} \rightarrow{ }^{234} \mathrm{U} \rightarrow{ }^{230} \mathrm{Th} \rightarrow{ }^{226} \mathrm{Ra}$ released from a high-level waste (HLW) repository. Table 1 summarizes the transport parameters related to our illustrative example. A homogeneous saturated aquifer of size $L \times W \times H=250 \mathrm{~m} \times 100 \mathrm{~m} \times 100 \mathrm{~m}$, as shown in Figure 2, is considered. The values of retardation factors used in Table 1 were adopted from Higashi and Pigford [51] and van Genuchten [26]. The rectangular patch boundary source at the inflow boundary is arranged on $40 m \leq y \leq 60 m$ and $0 m \leq z \leq 100 m$ segments of the inflow source boundary $x=0 \mathrm{~m}$. Figures 3 and 4 depict a spatial concentration profile along the groundwater flow direction $(y=50 \mathrm{~m})$ and two spatial concentration profiles perpendicular to the groundwater flow direction ( $x=25 \mathrm{~m}$ and $x=50 \mathrm{~m}$ ) at $t=1000$ years and 10,000 years, respectively, as obtained from our derived analytical model and the analytical model developed by Chen et al. [44]. Chen et al. [44] derived the analytical solutions to the two-dimensional advection-dispersion equations coupled with sequential first-order decay reactions in a finite-length groundwater system. Numerical evaluation of their solution was always time-consuming and seems computationally inefficient due to the solutions involving summations of infinite series expansion. To reduce the impact of exit boundary on the radioactivity concentration of each individual radionuclide, the spatial concentration profiles perpendicular to the groundwater flow direction were selected far away from the finite-domain exit boundary. It can be seen that the spatial concentration profiles of four radionuclides along the groundwater flow direction and the two spatial concentration profiles perpendicular to groundwater flow direction obtained from our derived analytical model and Chens et al.'s [44] solution coincide closely to each other for a wide range of radioactivity concentrations. Excellent agreement between the two solutions clearly demonstrates the correctness of the derived analytical model and the robustness of the computer code. Subsequently, we have compared the computation times required for numerical evaluation of our solutions and Chens et al.'s [44] solutions. The computation time required for our analytical model was approximately one tenth of that required for Chen et al.'s [44] model, thus demonstrating the computation efficiency of our model. 
Table 1. Transport parameters used for verification involving two-dimensional reactive transport of a four-member radionuclide decay chain.

\begin{tabular}{|c|c|c|}
\hline Parameter & Unit & Value \\
\hline Domain length, $L$ & $\mathrm{~m}$ & 250 \\
\hline Domain width, $W$ & $\mathrm{~m}$ & 100 \\
\hline Domain height, $H$ & $\mathrm{~m}$ & 100 \\
\hline Groundwater velocity, $v$ & m/year & 100 \\
\hline Dispersion coefficient, $D_{x}$ & $\mathrm{~m}^{2} /$ year & 1000 \\
\hline Dispersion coefficient, $D_{y}$ & $\mathrm{~m}^{2} /$ year & 100 \\
\hline \multicolumn{3}{|l|}{ Retardation factor, $R_{i}$} \\
\hline${ }^{238} \mathrm{Pu}$ & & 10,000 \\
\hline${ }^{234} \mathrm{U}$ & & 14,000 \\
\hline $230 \mathrm{Th}$ & & 50,000 \\
\hline${ }^{226} \mathrm{Ra}$ & & 500 \\
\hline \multicolumn{3}{|l|}{ Radioactive decay constant, $\lambda_{i}$} \\
\hline${ }^{234} \mathrm{U}$ & year $^{-1}$ & 0.0000028 \\
\hline 230Th & year $^{-1}$ & 0.0000087 \\
\hline${ }^{226} \mathrm{Ra}$ & year $^{-1}$ & 0.00043 \\
\hline \multicolumn{3}{|l|}{ Initial amount of nuclide, $M^{0}$} \\
\hline${ }^{238} \mathrm{Pu}$ & $\mathrm{Bq} / \mathrm{m}^{2}$ & $1.5 \times 10^{15}$ \\
\hline${ }^{234} \mathrm{U}$ & & 0 \\
\hline 230Th & & 0 \\
\hline${ }^{226} \mathrm{Ra}$ & & 0 \\
\hline \multicolumn{3}{|l|}{ Proportionality constant, $\gamma_{i}$} \\
\hline${ }^{238} \mathrm{Pu}$ & year $^{-1}$ & 0.001 \\
\hline${ }^{234} \mathrm{U}$ & year $^{-1}$ & 0.001 \\
\hline 230Th & year $^{-1}$ & 0.001 \\
\hline${ }^{226} \mathrm{Ra}$ & year $^{-1}$ & 0.001 \\
\hline \multicolumn{3}{|l|}{ Ingestion dose coefficient, $D F_{i}$} \\
\hline${ }^{238} \mathrm{Pu}$ & $\mathrm{Sv} / \mathrm{Bq}$ & $2.3 \times 10^{-7}$ \\
\hline${ }^{234} \mathrm{U}$ & $\mathrm{Sv} / \mathrm{Bq}$ & $4.9 \times 10^{-8}$ \\
\hline 230Th & $\mathrm{Sv} / \mathrm{Bq}$ & $2.1 \times 10^{-7}$ \\
\hline${ }^{226} \mathrm{Ra}$ & $\mathrm{Sv} / \mathrm{Bq}$ & $2.8 \times 10^{-7}$ \\
\hline
\end{tabular}

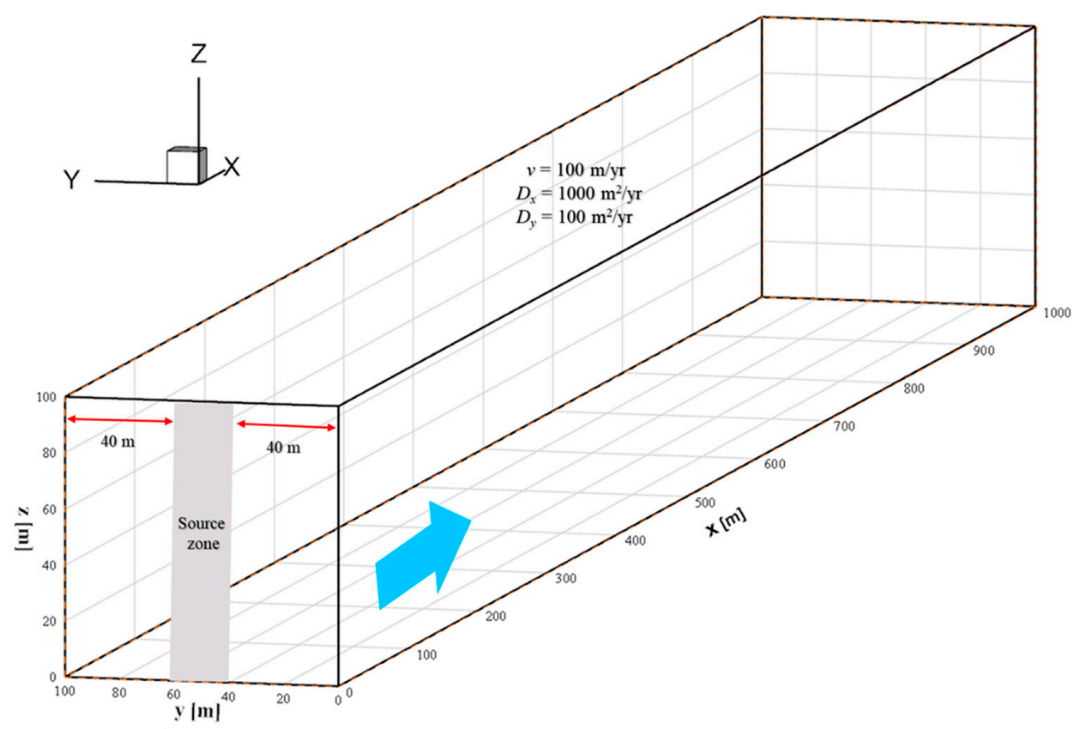

Figure 2. Schematic diagram of the verification scenario: radionuclide source is illustrated as square patch with dimensions of $40 \mathrm{~m} \leq y \leq 60 \mathrm{~m}$ and $0 \mathrm{~m} \leq z \leq 100 \mathrm{~m}$ at $x=0 \mathrm{~m}$. 

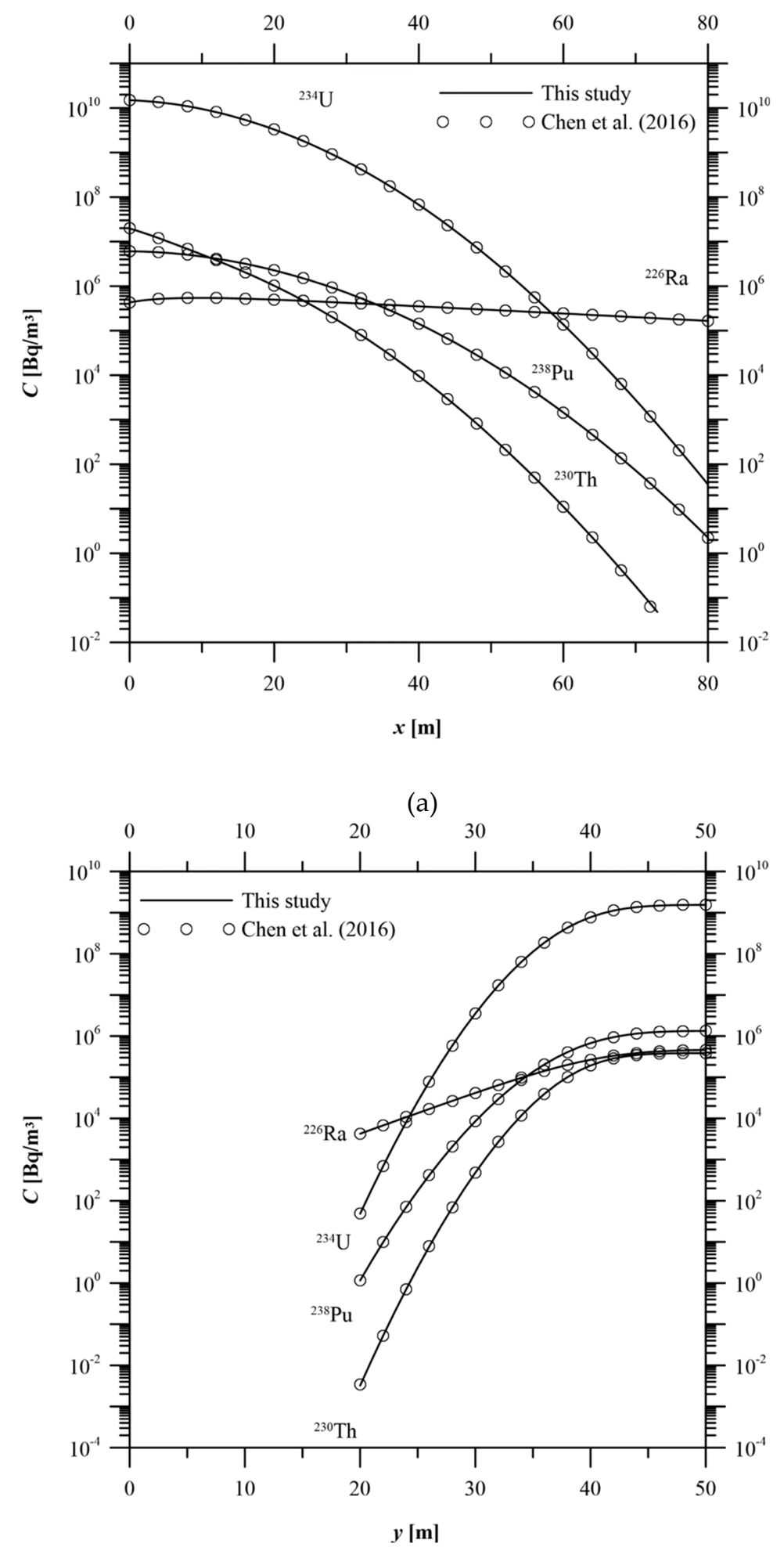

(b)

Figure 3. Cont. 


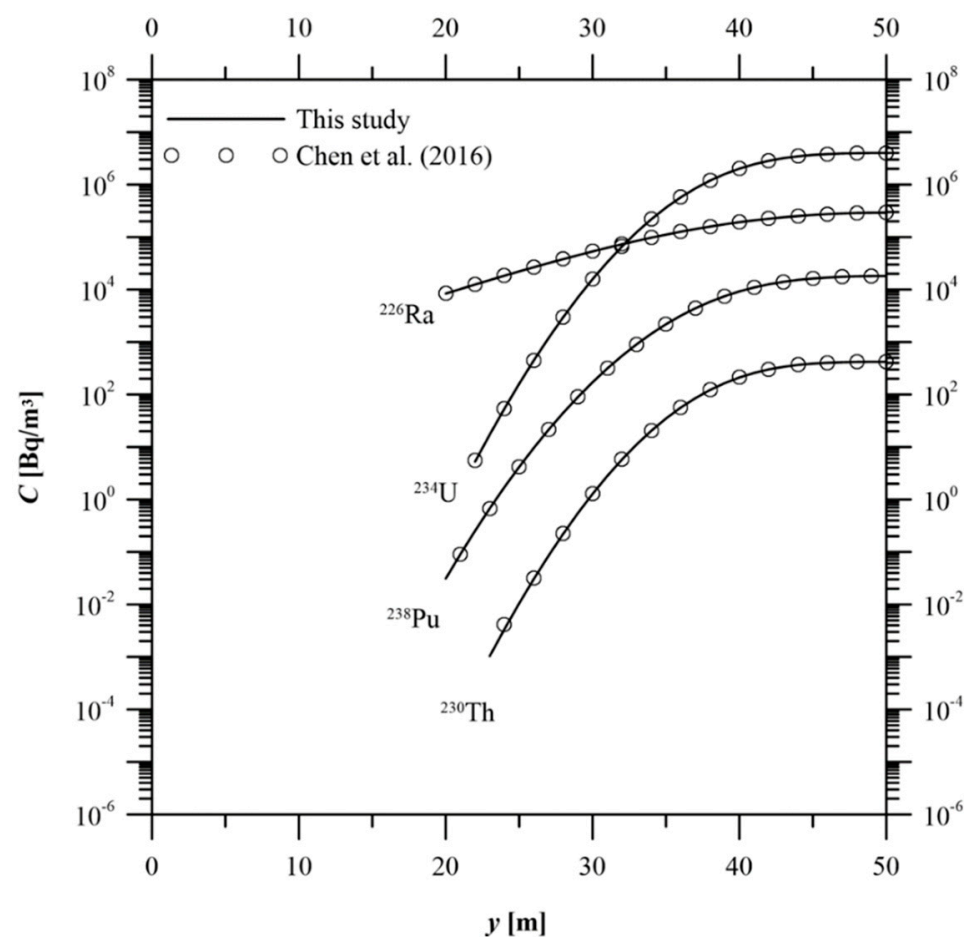

(c)

Figure 3. Comparison between spatial concentration profiles of a two-dimensional four-member decay chain migration at $t=1000$ years obtained from the derived analytical model and Chen et al.'s [14] analytical model at $\mathrm{t}=1000$ years: (a) along the groundwater flow direction $(y=50 \mathrm{~m})$; (b) perpendicular to the groundwater flow direction $(x=25 \mathrm{~m})$; (c) perpendicular to the groundwater flow direction $(x=50 \mathrm{~m})$.

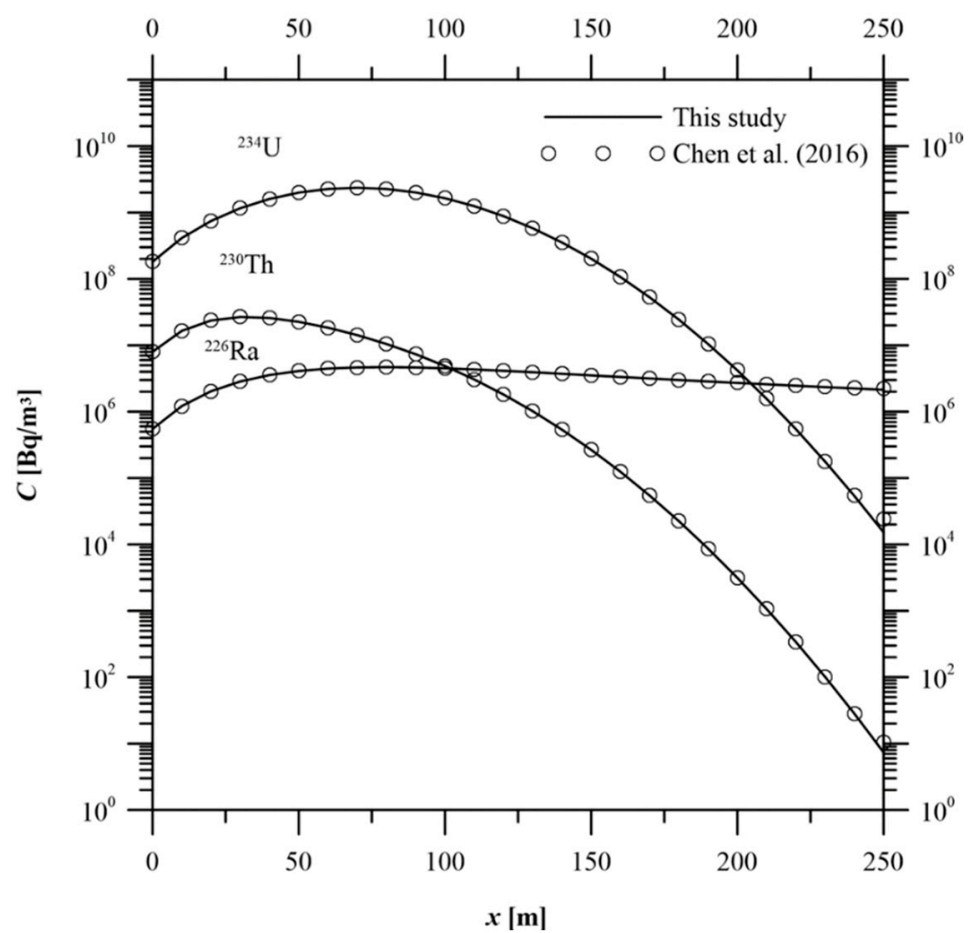

(a)

Figure 4. Cont. 


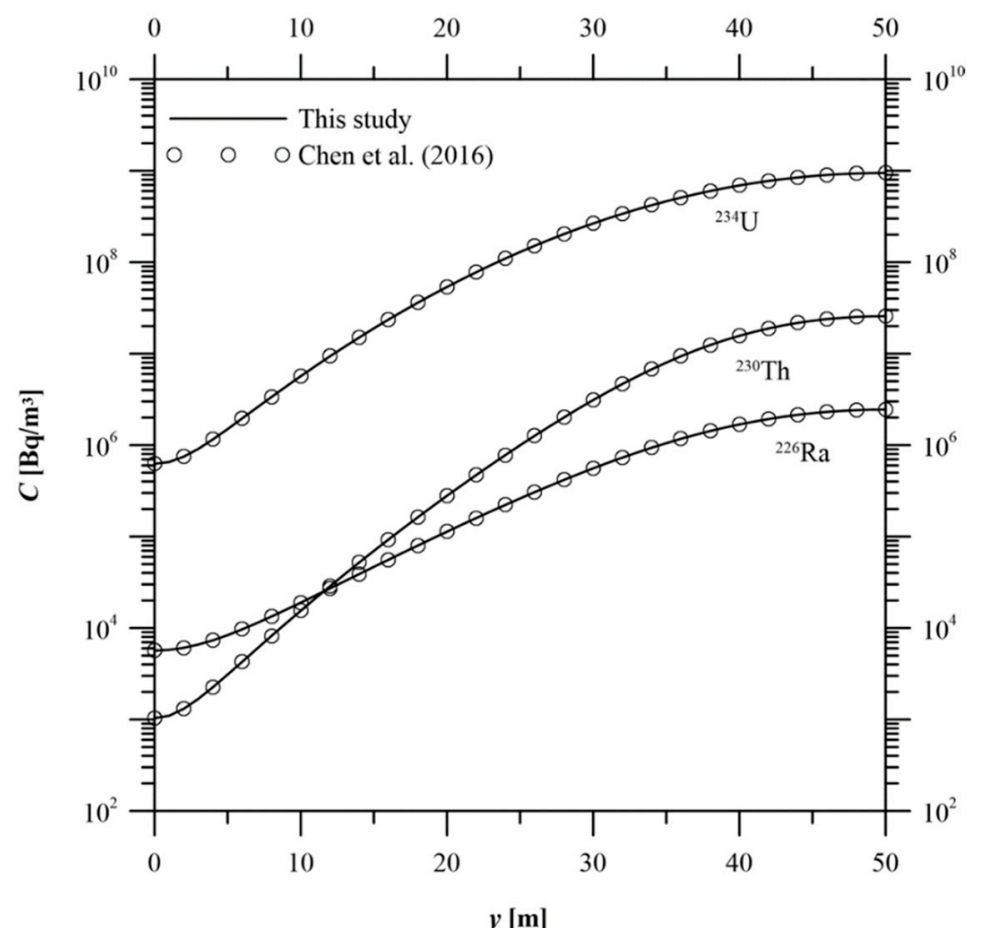

(b)

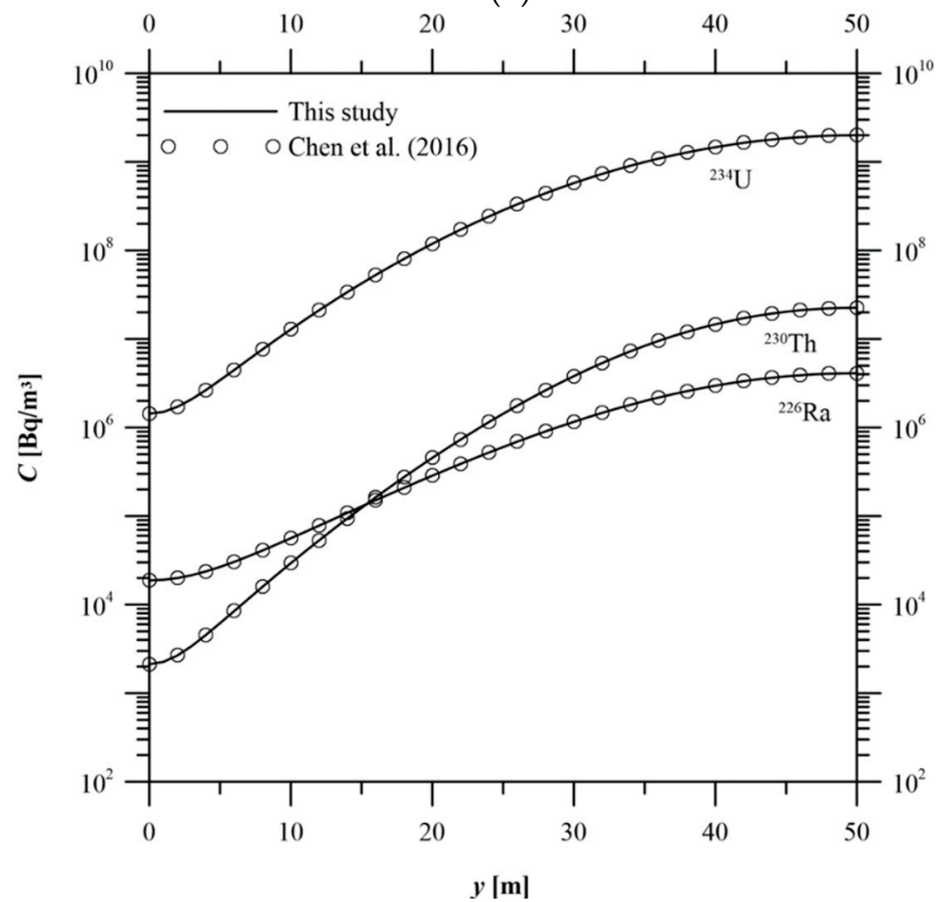

(c)

Figure 4. Comparison between spatial concentration profiles of a two-dimensional four-member decay chain migration at $t=10,000$ years obtained from the derived analytical model and Chen et al.'s [14] analytical model (a) along the groundwater flow direction ( $y=50 \mathrm{~m})$; (b) perpendicular to the groundwater flow direction $(x=25 \mathrm{~m})$; (c) perpendicular to the groundwater flow direction $(x=50 \mathrm{~m})$.

\subsection{Application of the Analytical Model}

After the verification exercise, the derived model was then employed to simulate the three-dimensional reactive transport of the same four-member radionuclide decay chain. The 
application example is similar to the verification example in that it simulates in two-dimensions the plume migration of a radionuclide decay chain, except for a slight modification of the inflow source. A schematic representation of the simulation scenario is shown in Figure 5. The simulation scenario considers a homogenous saturated groundwater system with a squared patch source at the inflow boundary. The geometry of the semifinite domain is in $L \times W \times H=\infty m \times 100 \mathrm{~m} \times 100 \mathrm{~m}$ dimensions. The square patch area is centered at $(y, z)=(50 \mathrm{~m}, 50 \mathrm{~m})$ and has a width and height of $20 \mathrm{~m}$ and $20 \mathrm{~m}$, respectively. The modeling parameters are the same as those used in the verification exercise. The application example was designed to demonstrate that the developed model can be used to compute the long-term three-dimensional transport behavior on both time and space scales. Figure 6 illustrates the spatial concentrations of the four nuclides in the radionuclide decay chain, at different depths, for a time period of $t=1000$ years. It is clearly observed that the migration distances of the four nuclide plumes are quite different. The ${ }^{226}$ Ra plume migrates a large distance because of its lower retardation factor that reflects its weaker sorption capacity as compared with the retardation factors of the other three nuclides. The fact that the difference in the behavior of the migrating plumes is significantly affected by the retardation factors of the individual nuclides shows the importance of accounting for different retardation factors for different nuclides in the modeling of the radionuclide decay chain.

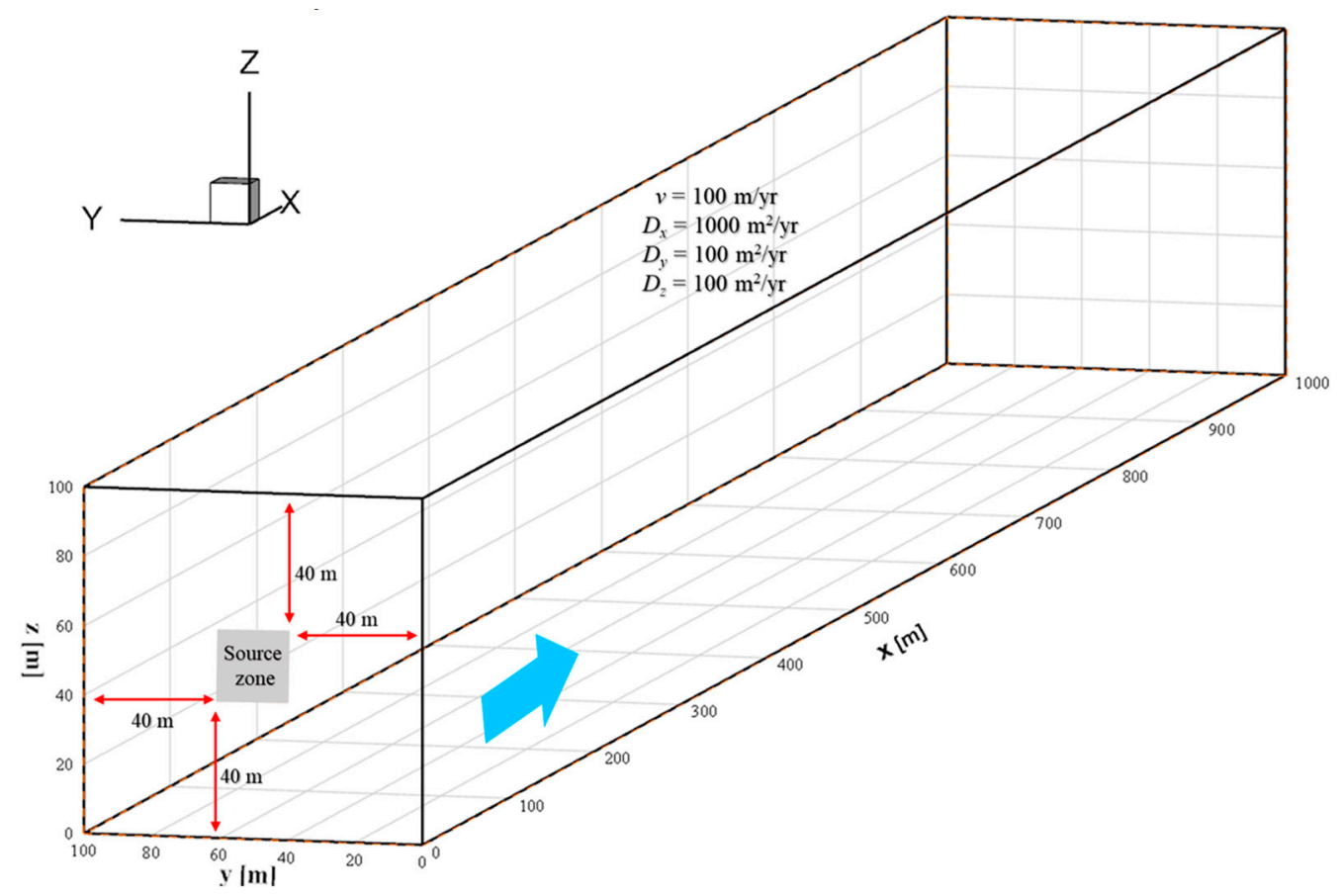

Figure 5. Schematic diagram of the simulation scenario: radionuclide source is illustrated as square patch with dimensions of $40 \mathrm{~m} \leq y \leq 60 \mathrm{~m}$ and $40 \mathrm{~m} \leq z \leq 60 \mathrm{~m}$ at $x=0 \mathrm{~m}$. 
(a) ${ }^{238} \mathrm{Pu}$

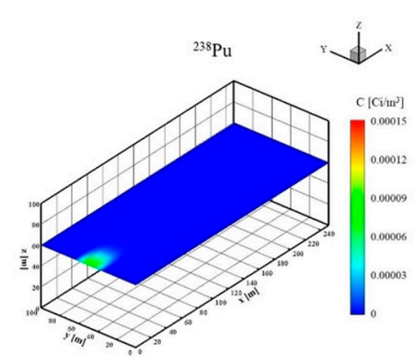

$z=60 m$

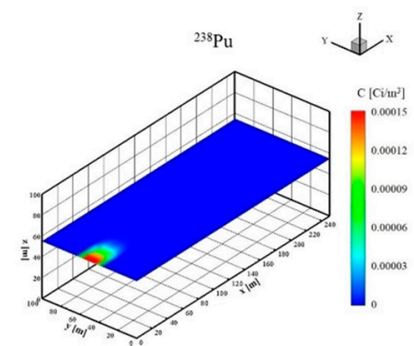

$z=55 m$

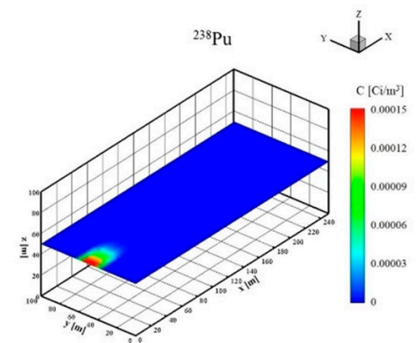

$z=50 m$ (b) ${ }^{234} \mathrm{U}$

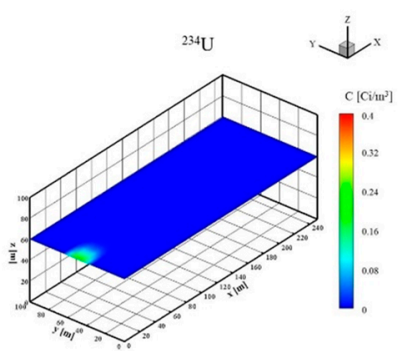

$z=60 m$

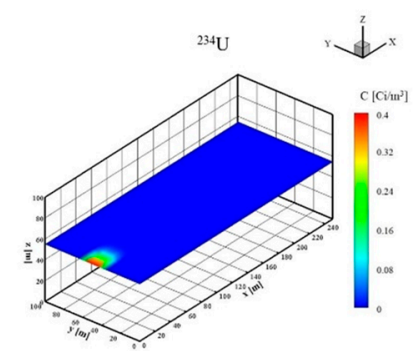

$z=55 m$

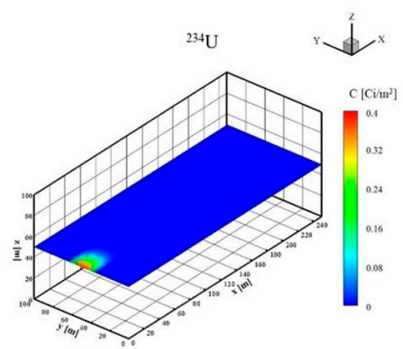

$z=50 m$

Figure 6. Cont. 
(c) ${ }^{230} \mathrm{Th}$

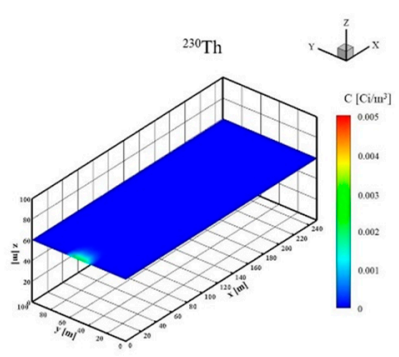

$z=60 m$

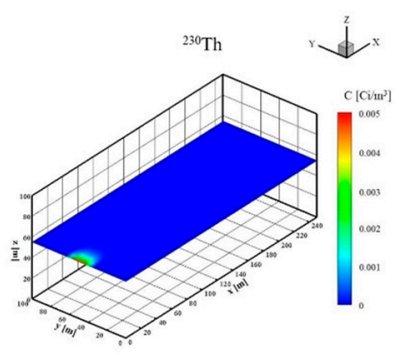

$z=55 m$

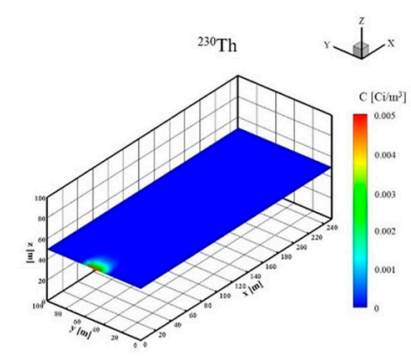

$z=50 \mathrm{~m}$ (d) ${ }^{226} \mathrm{Ra}$

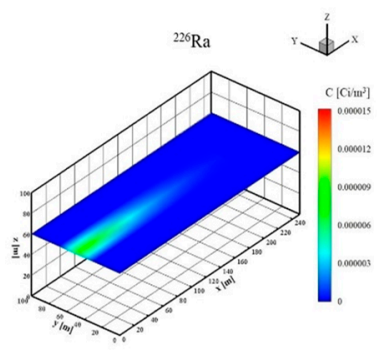

$z=60 m$

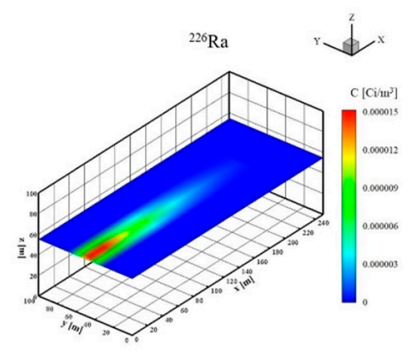

$z=55 m$

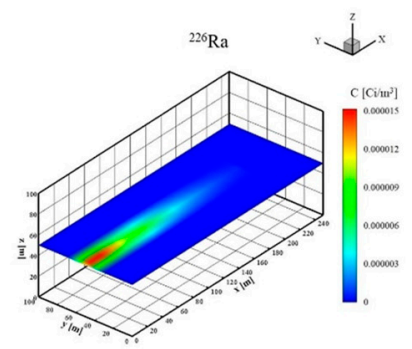

$z=50 m$

Figure 6. The concentration contours of each member of a four-member decay chain at $t=1000$ years. (a) ${ }^{238} \mathrm{Pu}$; (b) ${ }^{234} \mathrm{U}$; (c) ${ }^{230} \mathrm{Th}$; (d) ${ }^{226} \mathrm{Ra}$.

The concentrations of these radionuclides as a function of time at different distances $(x=100,250$ and $500 \mathrm{~m}$ ) from the inflow source boundary are depicted in Figure 7 . The concentration of ${ }^{238} \mathrm{Pu}$ at $x$ $=100 \mathrm{~m}$ increases in the early time period by start of decaying after about 1800 years and ultimately reaches a negligible value after about 5200 years, whereas the concentrations of ${ }^{234} U,{ }^{230 T h}$, and ${ }^{226} \mathrm{Ra}$ maintain the increasing trends up to 10,000 years. It is seen that ${ }^{226} \mathrm{Ra}$ has the highest radioactivity concentration before 3000 years, while the concentration of ${ }^{234} \mathrm{U}$ is greater than either ${ }^{230} \mathrm{Th}$ or ${ }^{226} \mathrm{Ra}$ up to 3000 years. The concentration at $\mathrm{x}=250 \mathrm{~m}$ of ${ }^{238} \mathrm{Pu}$ is exceedingly low and is not shown in Figure $7 \mathrm{~b}$. The concentrations of the other three nuclides increase up to 10,000 years and follow the order ${ }^{226} \mathrm{Ra}>$ ${ }^{234} \mathrm{U}>{ }^{230} \mathrm{Th}$. The concentration at $\mathrm{x}=500 \mathrm{~m}$ of ${ }^{226} \mathrm{Ra}$ increases up to 10,000 years, and ${ }^{234} \mathrm{U}$ and ${ }^{230} \mathrm{Th}$ reduce to $10^{-25} \mathrm{~Bq} / \mathrm{m}^{3}$ after 3000 and 5400 years. 


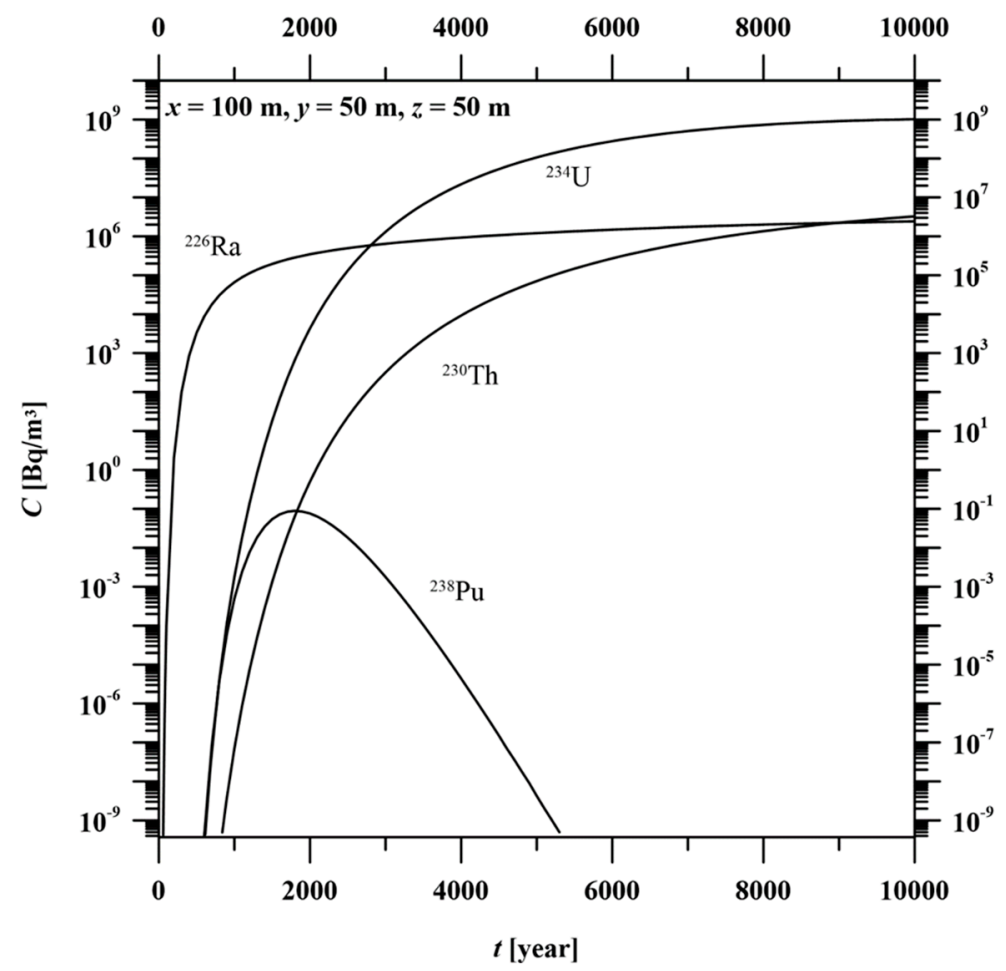

(a)

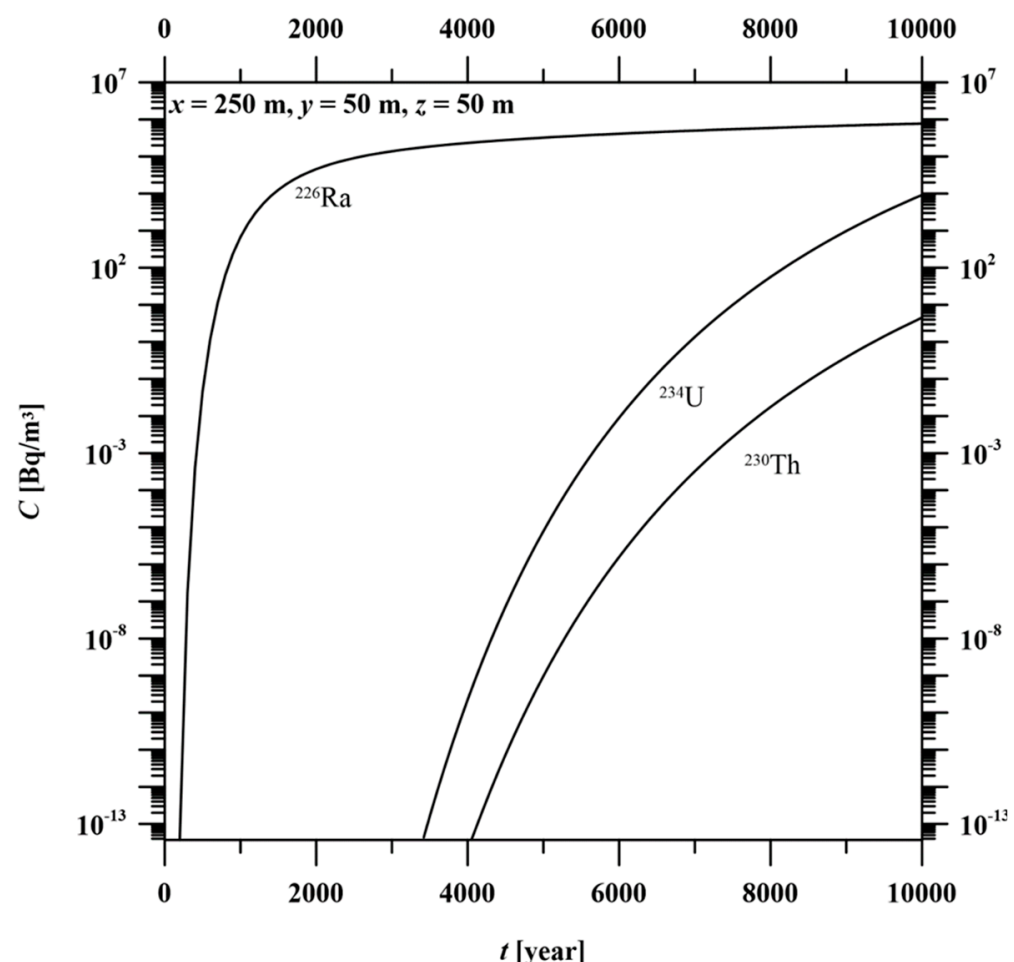

(b)

Figure 7. Cont. 


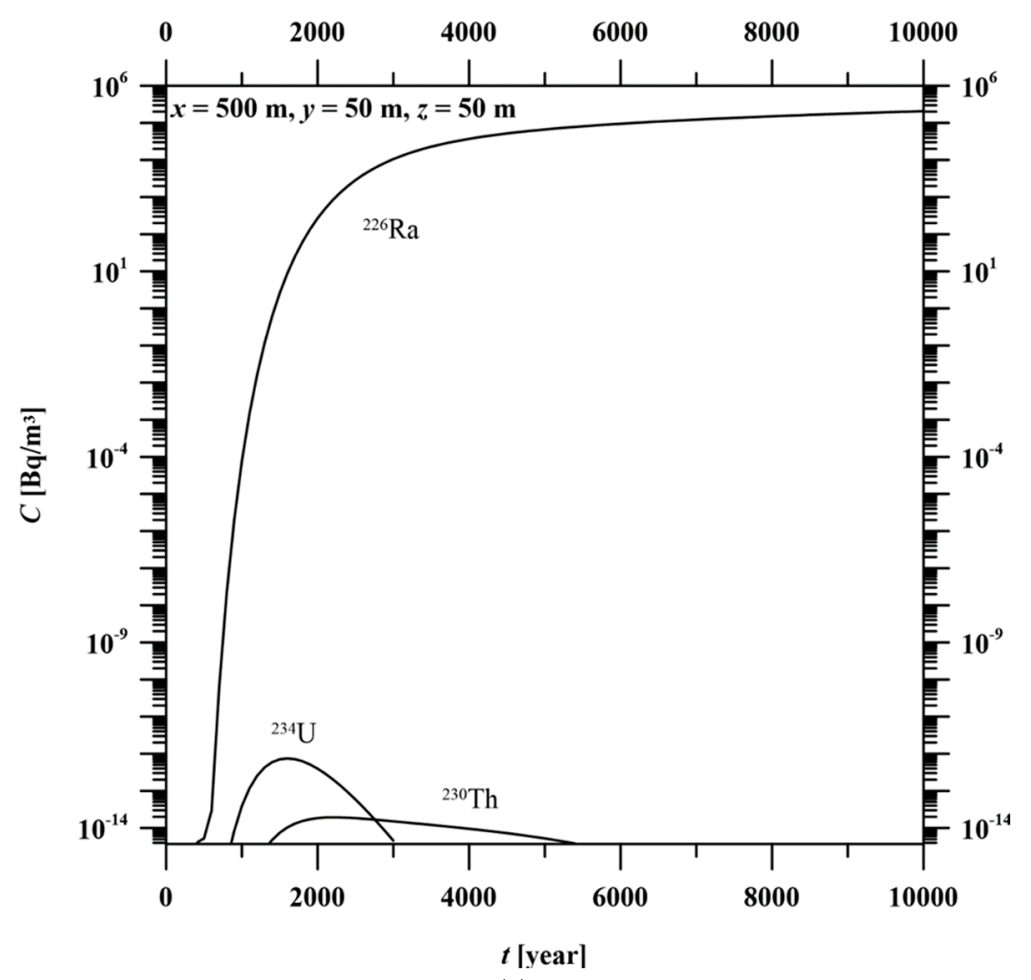

(c)

Figure 7. Time history of each member of a four-member decay chain at different distances from the inflow source boundary: (a) $x=100 \mathrm{~m}$; (b) $x=250 \mathrm{~m}$; (c) $x=500 \mathrm{~m}$.

Safety assessment of a radioactive waste repository requires an estimate of effective dose from multiple pathways, including ingestion of contaminated agricultural products grown with irrigated contaminated water and fishes, shell fishes, mollusk, and so on, living in contaminated surface water, originated from contaminated ground water. The model developed in this study only provides predictions of radionuclide concentrations in groundwater. It should be noted that consideration of radiological exposure from ingestion of drinking water is just a part of overall dose assessment. However, the greater intake comes from drinking contaminated water in many cases. The time histories of concentrations at different distances from the inflow source boundary, shown in Figure 7 are subsequently used to assess the committed effective dose rates consumed by members of the general public through ingestion of drinking water. The committed effective dose rate is equal to the product of concentration, drinking water ingestion rate, and the ingestion dose coefficient. Thus, the committed effective dose per person from a given radionuclide decay chain through groundwater can be calculated by

$$
\text { Committed effective dose }=\sum_{i=1}^{i=N} I R \times C_{i} \times D F_{i}
$$

where $I R$ is the rate of intake $\left[\mathrm{m}^{3} /\right.$ day $], C_{i}$ is the radioactivity concentration in groundwater of nuclide $i$ $\left[\mathrm{Bq} / \mathrm{m}^{3}\right]$, and $D F_{i}$ is the ingestion dose coefficient of nuclide $i$ for the adult age group [Sv/Bq].

The ingestion dose coefficients for the adult age group for individual nuclides in the radionuclide decay chain are adopted from ICRP [52] and included in Table 1. The corresponding time history of the total dose and the doses due to individual nuclides at different distances from the origin are given in Figure 8. The magnitude of the doses for the different nuclides follows the same sequence of concentration magnitude as shown in Figure 7. For the distance of $x=100 \mathrm{~m},{ }^{226} \mathrm{Ra}$ contributes almost the total dose during the time period of 3000 years, whereas most of the total dose is contributed by ${ }^{234} \mathrm{U}$ after 3000 years. At a distance of $x=250 \mathrm{~m}$ and $500 \mathrm{~m}$, most of the total dose is contributed by ${ }^{226} \mathrm{Ra}$ throughout the entire time period. Comparison with the applicable guidelines show that the total 
annual doses at $x=100 \mathrm{~m}, 250 \mathrm{~m}$, and $x=500 \mathrm{~m}$ are all above the WHO guideline of $0.1 \mathrm{mSv} / \mathrm{year}$ for the drinking water pathway. The generalized analytical solutions can quickly and accurately predict the three-dimensional radionuclide plume migration and assess the radiological impact posed by radionuclides in the environment as a result of leakage from a nuclear waste repository or accidental discharge from a nuclear facility.

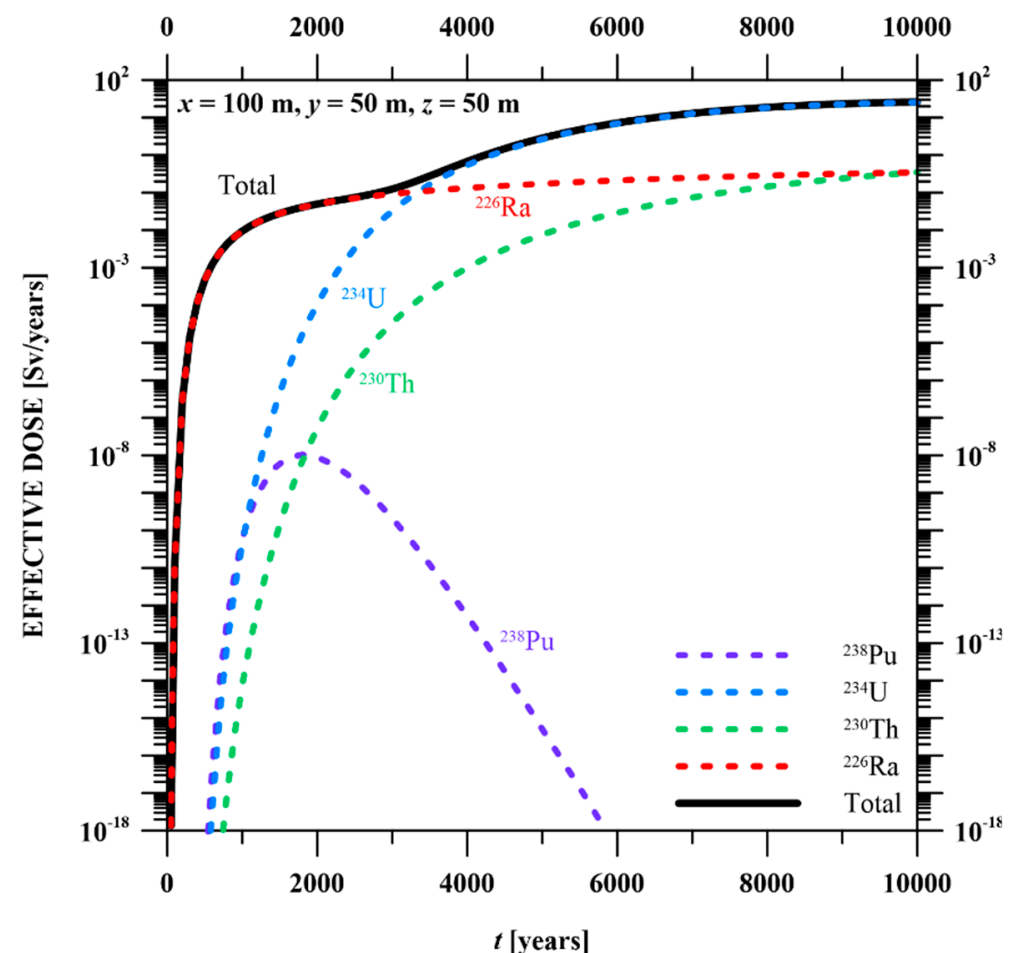

(a)

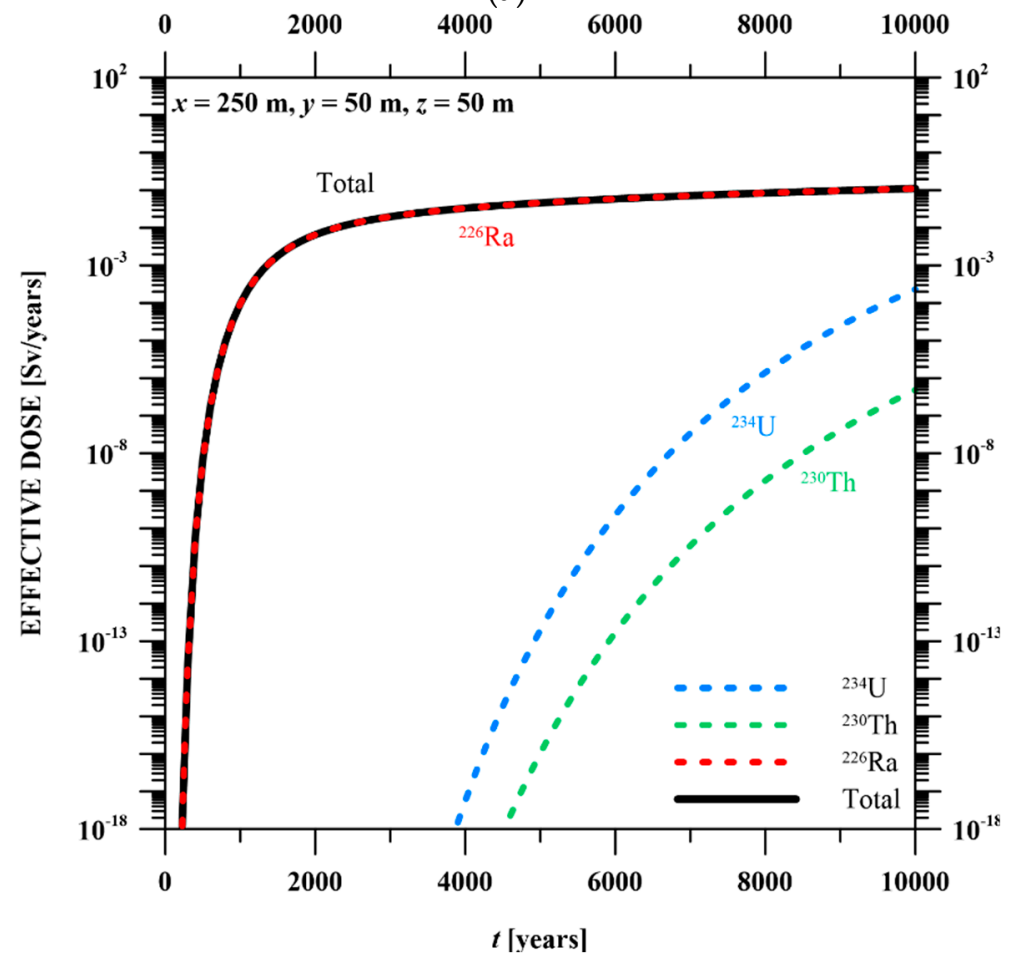

(b)

Figure 8. Cont. 


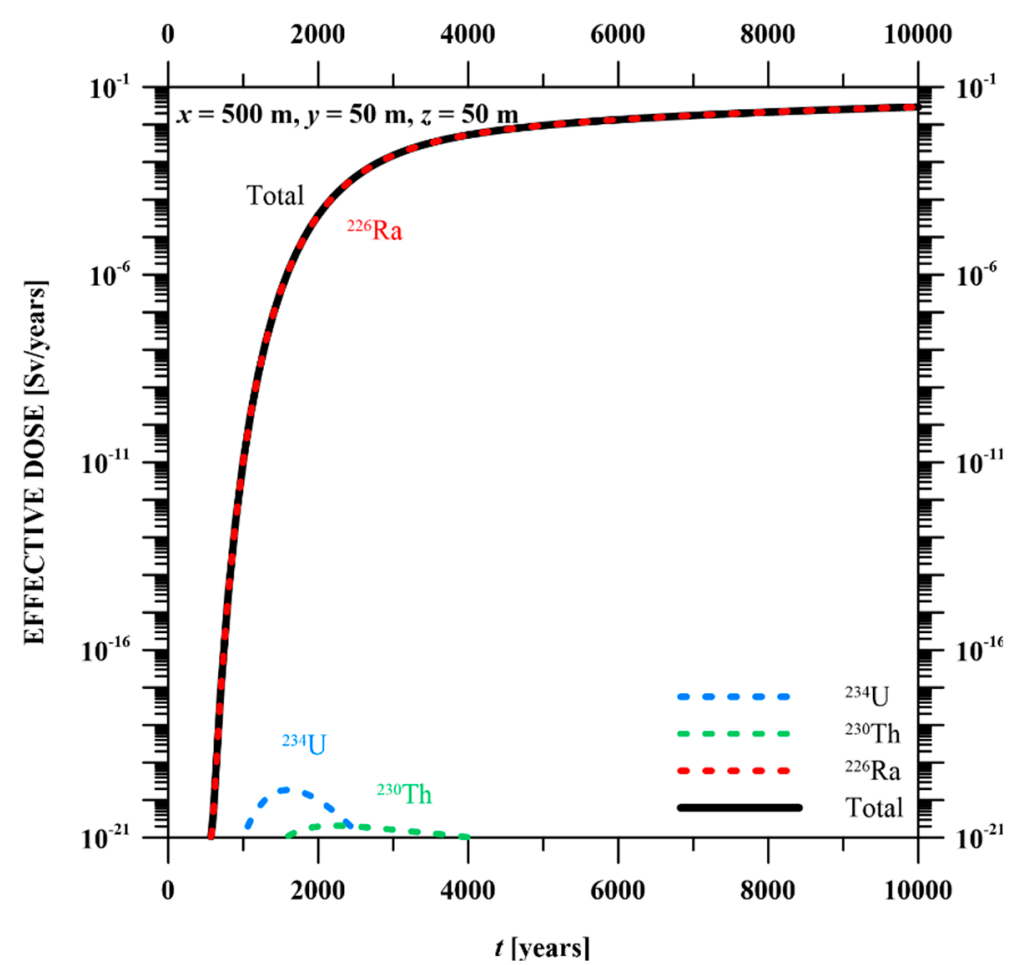

(c)

Figure 8. The total and individual effective dose of a four-member decay chain acquired through drinking groundwater pathway at different distances from the inflow source boundary: (a) $x=100 \mathrm{~m}$; (b) $x=250 \mathrm{~m}$; (c) $x=500 \mathrm{~m}$.

\section{Conclusions}

A novel semi-analytical model with parsimonious mathematical expression for modeling three-dimensional radioactivity transport of radionuclide decay chain is introduced in this study. The presented model can simultaneously simulate the radioactivity concentrations of each member of a radionuclide decay chain. The model verification is confirmed with close coincidences between the spatial concentration profiles obtained from the derived semi-analytical model and an existing analytical model found in the literature. An illustrative example is employed to demonstrate the applicability of our developed semi-analytical model for simulating the three-dimensional plume migration and assessing the radiological dose of a radionuclide decay chain. Despite that there are a number of time-marching numerical models that can accommodate multiple radionuclide transport of a decay chain, our analytical model, which can synchronously evaluate the three-dimensional radioactivity concentrations of all members of a radionuclide decay chain at any desired time, without the step-by-step computation, should be especially useful as a rapid and effective tool for assessing long-term transport behavior as well as the radionuclide impact posed by radionuclides in the environment.

Author Contributions: C.-P.L. and J.-S.C. conceived and designed the study, J.-S.C. and C.-H.C. contributed to the development of the analytical model, C.P. designed the application example and radiological dose calculation, C.-P.L., J.S.C. and M.-H.W. interpreted the results, C.-P.L. and J.S. wrote the manuscript and made a critical revision.

Acknowledgments: The authors are grateful to Ministry of Science and Technology, Republic of China, for their financial support of this research under contract MOST 107-2623-E-008-003 -NU.

Conflicts of Interest: The authors declare no conflicts of interest. 


\section{References}

1. Yeh, G.T. AT123D: Analytical Transient One-, Two-, and Three-Dimensional Simulation of Waste Transport in the Aquifer System, ORNL-5602; Oak Ridge National Laboratory: Oak Ridge, TN, USA, 1981.

2. Van Genuchten, M.T.; Alves, W.J. Analytical Solutions of the One-Dimensional Convective-Dispersive Solute Transport Equation; Technical Bulletin No. 1661; US Department of Agriculture: Washington, DC, USA, 1982.

3. Batu, V. A generalized two-dimensional analytical solution for hydrodynamic dispersion in bounded media with the first-type boundary condition at the source. Water Resour. Res. 1989, 25, 1125-1132. [CrossRef]

4. Batu, V. A generalized two-dimensional analytical solute transport model in bounded media for flux-type finite multiple sources. Water Resour. Res. 1993, 29, 2881-2892. [CrossRef]

5. Batu, V. A generalized three-dimensional analytical solute transport model for multiple rectangular first-type sources. J. Hydrol. 1996, 174, 57-82. [CrossRef]

6. Leij, F.J.; Skaggs, T.H.; Van Genuchten, M.T. Analytical solution for solute transport in three-dimensional semi-infinite porous media. Water Resour. Res. 1991, 27, 2719-2733. [CrossRef]

7. Leij, F.J.; Toride, N.; van Genuchten, M.T. Analytical solutions for non-equilibrium solute transport in three-dimensional porous media. J. Hydrol. 1993, 151, 193-228. [CrossRef]

8. Park, E.; Zhan, H. Analytical solutions of contaminant transport from finite one-, two, three-dimensional sources in a finite thickness aquifer. J. Contam. Hydrol. 2001, 53, 41-61. [CrossRef]

9. Chen, J.S.; Liu, C.W.; Liao, C.M. A novel analytical power series solution for solute transport in a radially convergent flow field. J. Hydrol. 2002, 266, 120-138. [CrossRef]

10. Chen, J.S.; Ni, C.F.; Liang, C.P.; Chiang, C.C. Analytical power series solution for contaminant transport with hyperbolic asymptotic distance-dependent dispersivity. J. Hydrol. 2008, 362, 142-149. [CrossRef]

11. Chen, J.S.; Ni, C.F.; Liang, C.P. Analytical power series solutions to the two-dimensional advection-dispersion equation with distance-dependent dispersivities. Hydrol. Process. 2008, 22, 4670-4678. [CrossRef]

12. Chen, J.S.; Chen, J.T.; Liu, C.W.; Liang, C.P.; Lin, C.M. Analytical solutions to two-dimensional advection-dispersion equation in cylindrical coordinates in finite domain subject to first- and third-type inlet boundary conditions. J. Hydrol. 2011, 405, 522-531. [CrossRef]

13. Chen, J.S.; Liu, Y.H.; Liang, C.P.; Liu, C.W.; Lin, C.W. Exact analytical solutions for two-dimensional advection-dispersion equation in cylindrical coordinates subject to third-type inlet boundary condition. Adv. Water Resour. 2011, 34, 365-374. [CrossRef]

14. Chen, J.S.; Hsu, S.Y.; Li, M.H.; Liu, C.W. Assessing the performance of a permeable reactive barrier-aquifer system using a dual-domain solute transport model. J. Hydrol. 2016, 543, 849-860. [CrossRef]

15. Chen, J.S.; Li, L.Y.; Lai, K.H.; Liang, C.P. Analytical model for advective-dispersive transport involving flexible boundary inputs, initial distributions and zero-order productions. J. Hydrol. 2017, 554, 187-199. [CrossRef]

16. Zhan, H.; Wen, Z.; Gao, G. An analytical solution of two-dimensional reactive solute transport in an aquifer-aquitard system. Water Resour. Res. 2009, 45, W10501. [CrossRef]

17. Pérez Guerrero, J.S.; Skaggs, T.H.; van Genuchten, M.T. Analytical solution for multi-species contaminant transport in finite media with time-varying boundary condition. Transp. Porous Med. 2010, 85, 171-188. [CrossRef]

18. Gao, G.; Zhan, H.; Feng, S.; Fu, B.; Ma, Y.; Huang, G. A new mobile-immobile model for reactive solute transport with scale-dependent dispersion. Water Resour. Res. 2010, 46, W08533. [CrossRef]

19. Gao, G.; Zhan, H.; Feng, S.; Huang, G.; Fu, B. A mobile-immobile model with an asymptotic scale-dependent dispersion function. J. Hydrol. 2012, 424, 172-183. [CrossRef]

20. Gao, G.; Fu, B.; Zhan, H.; Ma, Y. Contaminant transport in soil with depth-dependent reaction coefficients and time-dependent boundary conditions. Water Res. 2013, 47, 2507-2522. [CrossRef]

21. Chen, J.S.; Liu, C.W. Generalized analytical solution for advection-dispersion equation in finite spatial domain with arbitrary time-dependent inlet boundary condition. Hydrol. Earth Syst. Sci. 2011, 15, 2471-2479. [CrossRef]

22. Pérez Guerrero, J.S.; Pontedeiro, E.M.; van Genuchten, M.T.; Skaggs, T.H. Analytical solutions of the one-dimensional advection-dispersion solute transport equation subject to time-dependent boundary conditions. Chem. Eng. J. 2013, 221, 487-491. [CrossRef] 
23. Liang, C.P.; Hsu, S.Y.; Chen, J.S. An analytical model for solute transport in an infiltration tracer test in soil with a shallow groundwater table. J. Hydrol. 2016, 540, 129-141. [CrossRef]

24. Nair, R.N.; Sunny, F.; Manikandan, S.T. Modelling of decay chain transport in groundwater from uranium tailings ponds. Appl. Math. Model. 2010, 34, 2300-2311. [CrossRef]

25. Cho, C.M. Convective transport of ammonium with nitrification in soil. Can. J. Soil Sci. 1971, 51, 339-350. [CrossRef]

26. Van Genuchten, M.T. Convective-dispersive transport of solutes involved in sequential first-order decay reactions. Comput. Geosci. 1985, 11, 129-147. [CrossRef]

27. Lunn, M.; Lunn, R.J.; Mackay, R. Determining analytic solution of multiple species contaminant transport with sorption and decay. J. Hydrol. 1996, 180, 195-210. [CrossRef]

28. Sun, Y.; Clement, T.P. A decomposition method for solving coupled multi-species reactive transport problems. Transp. Porous Med. 1999, 37, 327-346. [CrossRef]

29. Sun, Y.; Peterson, J.N.; Clement, T.P. A new analytical solution for multiple species reactive transport in multiple dimensions. J. Contam. Hydrol. 1999, 35, 429-440. [CrossRef]

30. Sun, Y.; Petersen, J.N.; Clement, T.P.; Skeen, R.S. Development of analytical solutions for multi-species transport with serial and parallel reactions. Water Resour. Res. 1999, 35, 185-190. [CrossRef]

31. Srinivasan, V.; Clememt, T.P. Analytical solutions for sequentially coupled one-dimensional reactive transport problems-Part I: Mathematical derivations. Adv. Water Res. 2008, 31, 203-218. [CrossRef]

32. Srinivasan, V.; Clement, T.P. Analytical solutions for sequentially coupled one-dimensional reactive transport problems-Part II: Special cases, implementation and testing. Adv. Water Res. 31, 219-232. [CrossRef]

33. Pérez Guerrero, J.S.; Skaggs, T.H.; van Genuchten, M.T. Analytical solution for multi-species contaminant transport subject to sequential first-order decay reactions in finite media. Transp. Porous Med. 2009, 80, 373-387. [CrossRef]

34. Chen, J.S.; Lai, K.H.; Liu, C.W.; Ni, C.F. A novel method for analytically solving multi-species advective-dispersive transport equations sequentially coupled with first-order decay reactions. J. Hydrol. 2012, 420, 191-204. [CrossRef]

35. Chen, J.S.; Liu, C.W.; Liang, C.P.; Lai, K.H. Generalized analytical solutions to sequentially coupled multi-species advective-dispersive transport equations in a finite domain subject to an arbitrary time-dependent source boundary condition. J. Hydrol. 2012, 456-457, 101-109. [CrossRef]

36. Bauer, P.; Attinger, S.; Kinzelbach, W. Transport of a decay chain in homogeneous porous media: Analytical solutions. J. Contam. Hydrol. 2001, 49, 217-239. [CrossRef]

37. Montas, H.J. An analytical solution of the three-component transport equation with application to third-order transport. Water Resour. Res. 2003, 39, 1036. [CrossRef]

38. Quezada, C.R.; Clement, T.P.; Lee, K.K. Generalized solution to multi-dimensional multi-species transport equations coupled with a first-order reaction network involving distinct retardation factors. Adv. Water Res. 2004, 27, 507-520. [CrossRef]

39. Sudicky, E.A.; Hwang, H.T.; Illman, W.A.; Wu, Y.S. A semi-analytical solution for simulating contaminant transport subject to chain-decay reactions. J. Contam. Hydrol. 2013, 144, 20-45. [CrossRef]

40. Kreft, A.; Zuber, A. Comment on "Flux averaged and volume averaged concentrations in continuum approaches to solute transport". Water Resour. Res. 1986, 22, 1157-1158. [CrossRef]

41. Parker, J.C.; van Genuchten, M.T. Flux-averaged and volume-averaged concentrations in continuum approaches to solute transport. Water Resour. Res. 1984, 20, 866-872. [CrossRef]

42. Van Genuchten, M.T.; Parker, J.C. Boundary conditions for displacement experiments through short laboratory soil columns. Soil Sci. Soc. Am. J. 1984, 48, 703-708. [CrossRef]

43. Parlange, J.Y.; Barry, D.A.; Starr, J.L. Comments on "Boundary conditions for displacement experiments through short laboratory soil columns". Soil Sci. Soc. Am. J. 1985, 49, 1325. [CrossRef]

44. Chen, J.S.; Liang, C.P.; Liu, C.W.; Li, L.Y. An analytical model for simulating two-dimensional multispecies plume migration. Hydrol. Earth Sys. Sci. 2016, 20, 733-753. [CrossRef]

45. Huang, J.; Goltz, M.N. Solutions to equations incorporating the effect of rate-limited contaminant mass transfer on vadose zone remediation by soil vapor extraction. Water Resour. Res. 1999, 35, 879-883. [CrossRef]

46. Lai, K.H.; Liu, C.W.; Liang, C.P.; Chen, J.S.; Sie, B.R. A novel method for analytically solving a radial advection-dispersion equation. J. Hydrol. 2016, 542, 532-540. [CrossRef] 
47. Chen, J.S.; Ho, Y.C.; Liang, C.P.; Wang, S.W.; Liu, C.W. Semi-analytical model for coupled multispecies advective-dispersive transport subject to rate-limited sorption. J. Hydrol. 2019, 579, 124-164. [CrossRef]

48. Sneddon, I.H. The Use of Integral Transforms; McGraw-Hill: New York, NY, USA, 1972.

49. De Hoog, F.R.; Knight, J.H.; Stokes, A.N. An improved method for numerical inversion of Laplace transforms. SIAM J. Sci. Stat. Comput. 1982, 3, 357-366. [CrossRef]

50. Chen, J.S.; Chen, C.S.; Chen, C.Y. Analysis of solute transport in a divergent flow tracer test with scale-dependent dispersion. Hydrol. Process. 2007, 21, 2526-2536. [CrossRef]

51. Higashi, K.; Pigford, T. Analytical models for migration of radionuclides in geological sorbing media. J. Nucl. Sci. Technol. 1980, 17, 700-709. [CrossRef]

52. ICRP. Compendium of Dose Coefficients based on ICRP Publication 60; ICRP Publication: Ottawa, ON, Canada, 2012.

(C) 2019 by the authors. Licensee MDPI, Basel, Switzerland. This article is an open access article distributed under the terms and conditions of the Creative Commons Attribution (CC BY) license (http://creativecommons.org/licenses/by/4.0/). 